\title{
Effects of Astaxanthin on Body and Liver Weight of High-Fat Diet through Regulation of Peroxisome Proliferator-Activated Receptors (PPARs)
}

\author{
Duy Nguyen-Le ${ }^{1,2}$, My-Tien Ngo ${ }^{1,2}$, Minh-Tuan Vo ${ }^{1,2}$, Thuoc Linh Tran ${ }^{1,2}$, Hieu Tran-Van ${ }^{1,2^{*}}$ \\ ${ }^{1}$ Department of Molecular and Environmental Biotechnology, Faculty of Biology and Biotechnology, University of \\ Science, Ho Chi Minh City, Vietnam \\ ${ }^{2}$ Vietnam National University, Ho Chi Minh City, Vietnam
}

\begin{abstract}
*Address for Correspondence: Dr. Hieu Tran-Van, Associate Professor, Faculty of Biology and Biotechnology, HCMC University of Science, Vietnam National University, HCM city, Vietnam

E-mail: tvhieu@hcmus.edu.vn ; Fax Number: +842838350096
\end{abstract}

Received: 26 Sep 2019/ Revised: 27 Dec 2019/ Accepted: 24 Feb 2020

\begin{abstract}
Background: Astaxanthin (ASTA) is a natural compound well-known for regulating lipid metabolism in the liver, specifically in reducing hepatosteatosis and weight control. In this study, we evaluated the ability to prevent hepatosteatosis and to stabilize body weight of ASTA.

Methods: Mice fed a high-fat diet (HFD) were orally given ASTA at a dosage of $30 \mathrm{mg} / \mathrm{kg}$ body weight/day in 16 weeks, following eight weeks of ASTA termination. Fat and liver tissues were collected at week $8,12,16$ and $24^{\text {th }}$ week of the trial. RT-qPCR was performed to determine the expression of PPARs in liver tissues.

Results: After 24 weeks, unexpectedly, ASTA supplied group (AX) caused excess weight gain since $12^{\text {th }}$ week, shown in higher average body weight than the HFD group. The result of liver weight was in line with the ratio of liver/body weight within experimental groups as they share the same tendency. However, the liver ratios and hepatosteatosis status were independent, yet even with $A X$, the $A X^{\prime}$ liver was still non-steatosis mostly relied on the protection of ASTA. The impacts of ASTA on HFD fed mice also showed effectiveness in preventing hepatosteatosis through down-regulating PPARy and stabilizing PPAR (liver receptors regulating fat metabolism).

Conclusion: This made ASTA a good player for liver lipid homeostasis, but not for weight control. Taken together, ASTA was a potential compound for preventing hepatitis steatosis.
\end{abstract}

Key-words: Astaxanthin, ASTA, Hepatosteatosis, High-Fat Diet, Obese, PPAR, Weight control

\section{INTRODUCTION}

In hepatocytes, there are many peroxisome activated receptors in the cell nucleus, called Peroxisome Proliferator-Activated Receptors (PPAR), which consist of three types: $\alpha, \gamma$ and $\delta / \beta^{[1]}$. But only PPAR $\alpha$ and PPAR $\gamma$ are reported to be involved in lipid metabolism by controlling the translation of hepatic enzyme induced genes $^{[2,3]}$.

\footnotetext{
How to cite this article

Nguyen-Le D, Ngo MT, Vo MT, Tran TL, Tran-Van H. Effects of Astaxanthin on Body and Liver Weight of High-Fat Diet through Regulation of Peroxisome Proliferator-Activated Receptors (PPARs). SSR Inst. Int. J. Life Sci., 2020; 6(2): 2502-2508.
}

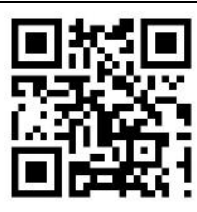

Access this article online https://iijls.com/
PPAR $\alpha$ mostly presents in the liver, where it regulates the activity of genes involved in fat breakdown. PPAR $\alpha$ governs the transportation and oxidation of fatty acids to reduce fat storage ${ }^{[4]}$. At the same time, PPAR $\alpha$ also regulates gluconeogenesis and amino acid metabolism ${ }^{[4]}$. On the other hand, PPAR $\gamma$, whose expression is high in fat cells, manipulates the activity of fat-storing genes in the liver ${ }^{[1]}$. According to Tailleux et al. ${ }^{[4]}$, losing a gene segment of PPARy leads to the protection of the liver from the risk of steatosis. When there is a large uptake of free fatty acids, eicosanoids, or complex lipid molecules, lipids are absorbed through the lymphatic system and transported to the liver. These molecules act as ligands that associate with hepatic metabolic receptors PPAR, leading to activation or inhibition of specific PPAR activities in the liver ${ }^{[5]}$. In patients with 
Non-Alcoholic Fatty Liver Diseases (NAFLD), PPAR $\alpha$ level in their liver decreased, whereas PPARy was highly expressed ${ }^{[5]}$.

Haematococcus pluvialis is well known for generating of the queen of oxidative suppression compound named astaxanthin. Many studies have shown that ASTA is an inducer of PPAR $\alpha$, and yet is an inhibitor of PPARY ${ }^{[1]}$. Therefore, ASTA is a natural compound that capable of regulating lipid metabolism in the liver. According to Jia's study, ASTA was also able to reduce two inflammatory factors, TNF- $\alpha$ and IL- 6 , both in plasma and liver, by activating the PPAR ${ }^{[1]}$. From there, it stopped the progression of Non-Alcoholic Fatty Liver (NAFL) to NonAlcoholic Steatohepatitis (NASH). NAFL and NASH were considered a stage of NAFLD ${ }^{[6]}$. Normally, NAFL progresses to NASH in the presence of inflammation and vice versa ${ }^{[7]}$. Thus, the presence of ASTA plays a crucial role in controlling inflammation. This stated that PPARs has effects in both lipid and inflammation regulation. Additionally, PPARs also showed roles in lipodystrophy, obesity, and insulin resistance ${ }^{[8]}$. Therefore, ASTA proved to be a potential natural compound for obesity and related diseases.

Due to the efficacy of lipid regulation, ASTA is predicted to have a role in weight controlling and liver weight by reduction of hepatosteatosis. In our previous unpublished data, there had been controversial results compared to the others on preventing weight gain of ASTA ${ }^{[1,9,10]}$. Our results showed, ASTA induced weight gain in Swiss female mouse model. Also, there has not been any result showed the effect of ASTA on liver weight. Therefore, in this research, we mainly focus on the impact of ASTA on the body weight and liver weight of mice to provide more data on ASTA for further study.

\section{MATERIALS AND METHODS}

Housing trial- The trial took place from February to August 2019, at the Department of Animal Physiology and Animal Biotechnology, HCMC University of Science, HCM city, Vietnam. Female Swiss mice (18-20 g), provided by the HCMC Drug Testing Institute, were randomly divided into three groups $(n=12)$ including normal diet (CTL, with $10 \%$ total calories from fat), highfat diet (HFD, with $60 \%$ total calories from fat) and highfat diet with ASTA supplementation (AX, $30 \mathrm{mg} / \mathrm{kg}$ body weight of ASTA). Mice were maintained on 12-hour light/dark cycle. The trial was divided into two phases. The first phase prolonged 16 weeks, mice were orally administrated with water (CTL and HFD group) or ASTA (AX group); the second phase prolonged 8 weeks, at which ASTA supplementation was terminated, but still maintaining the same diet. Mouse body weight was measured at the end of a week; food consumption was also recorded daily. Mice were dissected to obtain samples such as plasma, tissues. Dissection took place at week 8 th, 12 th, $16^{\text {th }}$ and $24^{\text {th }}$ to collect fat and liver tissues. Before samples were collected, mice were fasted for 12 hours before injected anesthetic.

Semi-quantitative RT-PCR analysis- The expression of PPAR genes was evaluated according to the protocol of Marone et al. ${ }^{[11]}$ with modifications. Briefly, liver tissues were homogenized using RNA isolation NucleoSpin ${ }^{\circ}$ RNA Plus (Macherey-Nagel) and the total RNA was extracted according to the manufacture's instruction. Then, cDNA was synthesized by mixing $3 \mu$ of total RNA $(300 \mu \mathrm{g} / \mathrm{ml})$ with MyTaq ${ }^{\text {TM }}$ One-Step RT-PCR Kit (Bioline). The cDNA of PPAR $\alpha$, PPAR $\gamma$, and $\beta$-actin was then amplified with the MyTaq Redmix PCR kit (Bioline) and specific primers (Table 1). PCR products were further analyzed through gel electrophoresis. The expression of marker genes was determined by normalizing the intensity of gel bands with $\beta$-actin and digitalized by ImageJ.

Table 1: Primer sequences used in semi quantitative RTPCR for liver tissue

\begin{tabular}{lll}
\hline Primers & \multicolumn{2}{c}{ Primer sequences } \\
\hline \multirow{2}{*}{ Beta actin } & $\begin{array}{l}\text { Forward } \\
\text { primer } \\
\text { Reverse } \\
\text { primer }\end{array}$ & GCTCTTTTCCAGCCTTCCTTC \\
& $\begin{array}{l}\text { Forward } \\
\text { primer } \\
\text { Alpha PPAR }\end{array}$ & ACCTTGTGTATGGCTCAGGAGGAG \\
& $\begin{array}{l}\text { Reverse } \\
\text { primer }\end{array}$ & AAGGAGGACAGCATCGTGAA \\
Forward & GAACCTGCATCTCCACCTTATT \\
Primer & Reverse & TGGAAGCCTGATGCTTTATCC \\
\hline
\end{tabular}

Statistical Analysis- All data are shown as the means \pm SEM with three-time replications, and one-way ANOVA were used to analyze the significant differences between the groups. The graphs were made using Graphpad. A value of $\mathrm{P}<0.05$ was considered significant. Along with that, ImageJ was used to analyze the presence of adipocyte in histiocytic liver. 
Ethical Approval- All mice were maintained in the experimental animal facility, and experiments were performed by following the guidelines provided by the Animal Care and Use Committee of University of Science, VNU-HCM.

\section{RESULTS}

Administration of ASTA induce the growth of Swiss albino mice- In the first and second stage (supplementation and termination of ASTA), the mice in AX group have started to grow bigger since week $12^{\text {th }}$, significantly different from HFD at week $16^{\text {th }}$ and reached its peak of oversize at week $24^{\text {th }}$ (Fig. 1A). CTL food consumption was the lowest among groups with $0.77 \pm 0.01 \mathrm{kcal}$ and $1.15 \pm 0.01 \mathrm{kcal}$ at week $16^{\text {th }}$ and $24^{\text {th }}$.
There was no significant difference between HFD and AX in food intake at week $16^{\text {th }}$ and $24^{\text {th }}$. HFD and AX were $5.35 \pm 0.05 \mathrm{kcal} ; 4.93 \pm 0.65 \mathrm{kcal}$ and $5.95 \pm 0.16 \mathrm{kcal}$; $5.52 \pm 0.80 \mathrm{kcal}$, respectively. Yet the weight gaining rate and of AX group was much faster and higher than HFD and the visceral fat of $A X$ also accumulated higher than others since week $16^{\text {th }}$ (Fig. 1B).

About the visceral fat, at week $8^{\text {th }}$ and $12^{\text {th }}$, there were no significant differences within groups, the greatest difference was at week $16^{\text {th }}$ when HFD and AX visceral fat grew higher $(5.64 \pm 0.59$ and $7.78 \pm 0.02 \mathrm{~g}$, respectively). Especially, AX reached its peak at $16^{\text {th }}$ week at $7.78 \pm 0.02$ g.
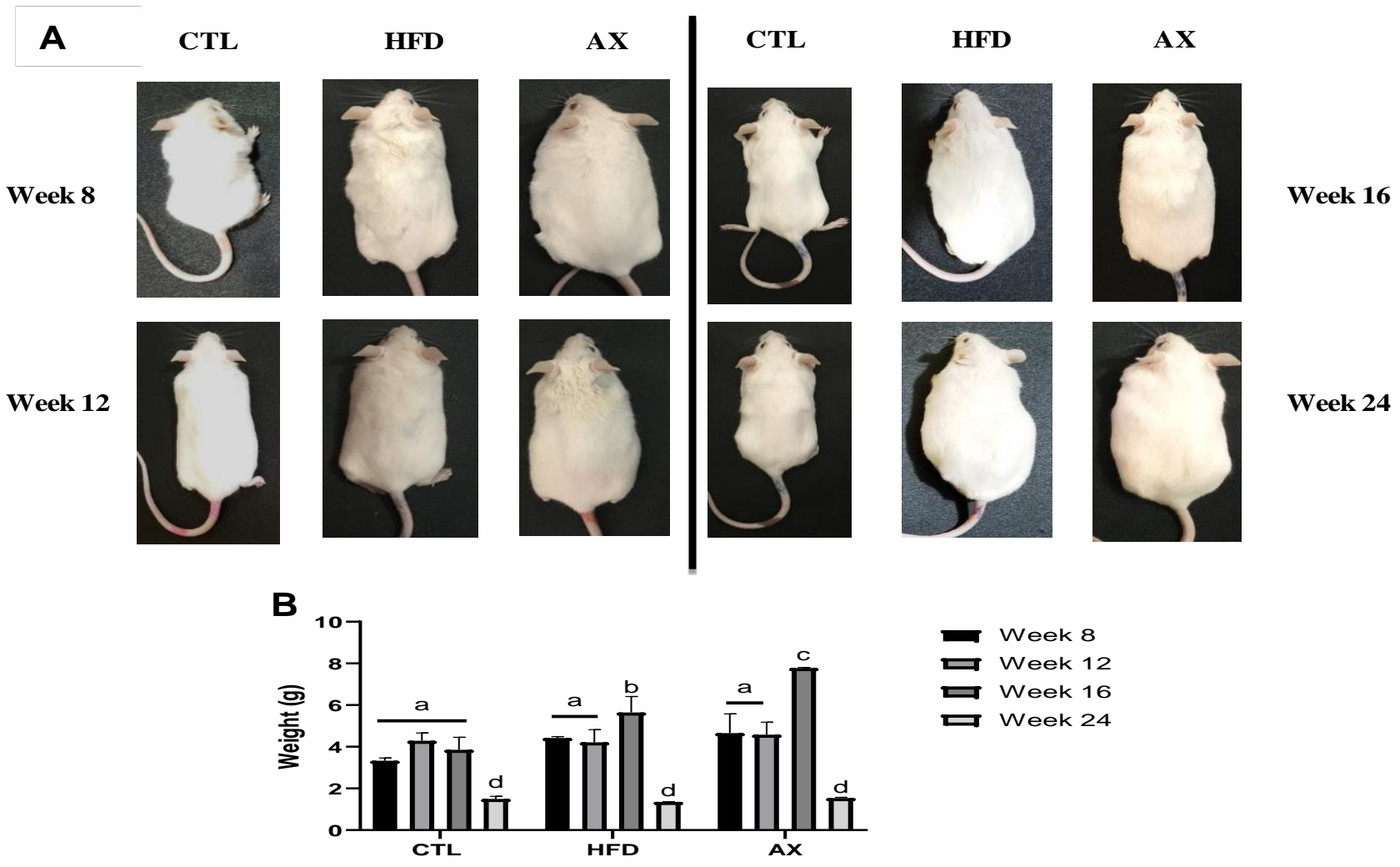

Fig. 1 (A): Shape of mice after 16- and 24-weeks trial, (B): Visceral fat of each mouse group after $8^{\text {th }}, 12^{\text {th }}, 16^{\text {th }}$ and $24^{\text {th }}$ week trialCTL, control group; HFD, high-fat diet group; AX, HFD with ASTA supplementation group

\section{Administration of ASTA reduced mice fat/body weight}

ratio- Overall, the ratios of liver weight and average weight between groups showed no differences in the first stage of the trial, except for AX had a slight decrease at week $16^{\text {th }}$ (Fig. 2). The obvious difference was after the second stage, where the ratio of HFD $(22.0 \pm 6.0 \%)$ and $A X(23.0 \pm 6.0 \%)$ were three times higher than $C T L$ $(6.1 \pm 0.2 \%)$. AX's liver weight reduced at $16^{\text {th }}$ week could base on the difference in enzyme induced mechanism ${ }^{[12]}$, which would be explained in the later section.
Our observation also detected that the liver weight and average weight of each group was independent with each other, as we noticed in CTL and HFD, even at low liver/body weight ratios, there were still evidence of hepatosteatosis and vice versa. Specifically, CTL at the early stage had healthy histologic livers (average ratio$A R=4.6$ ) then the liver becomes fatty in the middle of week $12^{\text {th }}(A R=4.9)$ but returned to normal $(A R=6.2)$ at the end. HFD mice's livers were steatosis at the very week $8^{\text {th }}$ and this continued to the end of the trial. 
On the contrary, $A X^{\prime}$ livers were in a completely healthy stage with no adipocyte presence. Plus, the ratio was in line with the actual liver weight. In general, there was a slight decrease in the ratio of $16^{\text {th }}$ week of $A X$, following with a sharp rise after $24^{\text {th }}$ week, this could be due to the effect of ASTA was lost after administration termination.

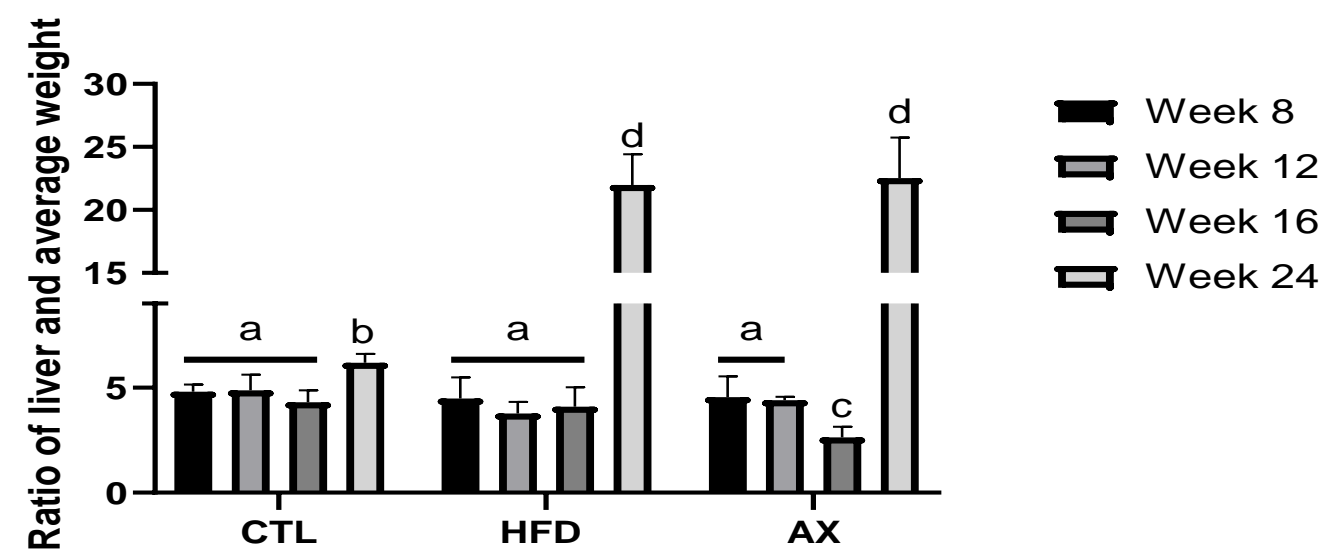

Fig. 2: The ratio of liver and average weight of each group at week 8, 12, 16 and 24. CTL,control group; HFD, high-fat diet group; AX,HFDwith ASTAsupplementation group. The data were presented as the means \pm SEM. Significant differences were calculated using a one-way ANOVA. Different letters indicate significant differences between the groups

Semi-quantitative RT-PCR analyzing- To further deduce the mechanism in which ASTA reducing liver weight by controlling PPARs, we performed semi quantitative RTPCR analyzing on PPAR $\alpha$ and PPAR encoded gene. There were distinct pattern variations of PPAR $\alpha$ and PPAR intensity after gel electrophoresis. PPAR $\alpha$ showed high intensity between HFD and AX from the $16^{\text {th }}$ week to $24^{\text {th }}$ week, while the AX's PPARy was equivalently low expression compared to CTL at $16^{\text {th }}$ week (Fig. 3). Both CTL and HFD stayed the lowest and highest group of PPAR $\alpha$ and PPARy at $16^{\text {th }}$ week and $24^{\text {th }}$ week, respectively. For AX, PPAR $\alpha$ expression was high during 8 weeks after ASTA termination (8244 \pm 463 ; 9579 \pm 700 of intensity, at $16^{\text {th }}$ and $24^{\text {th }}$ week, respectively), whereas PPARy was low $(2121 \pm 80)$ at $16^{\text {th }}$ week and rose to $4762 \pm 39$ at $24^{\text {th }}$ week. The high expression of PPAR $\alpha$ in HFD and AX were adaptive/protective response of PPAR $\alpha$ under high-fat diet in wild type mouse, as reported by the Lee ${ }^{[10]}$ and Kersten ${ }^{[13]}$. For $A X$, the low expression of PPARY also well correlated with the liver weight through the decreasing at week $16^{\text {th }}$, and increasing at $24^{\text {th }}$ week of the liver weight (Fig. 2). PPARy relates to genes that translate protein (including enzymes) for fat converting in the liver. Therefore, suppressed PPARy expression resulted in losing liver weight and vice versa.
A

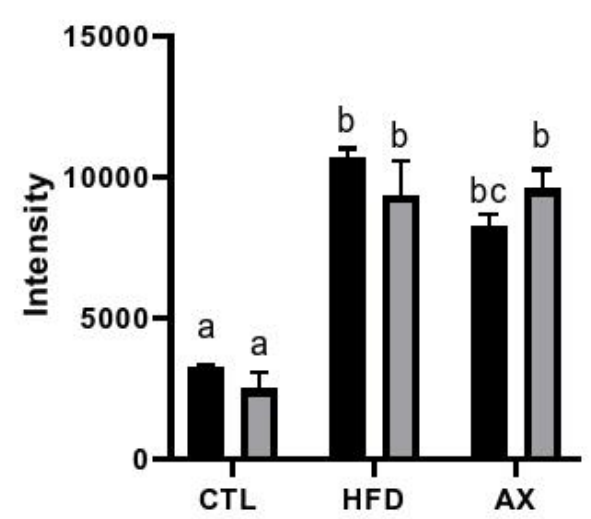

B

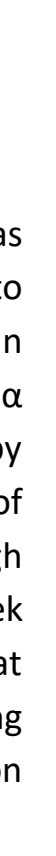




\section{DISCUSSION}

Astaxanthin, a natural compound, was reported in a few studies that can control both weight gain and lipid related problems induced by high-fat diet. Results obtained by Jia ${ }^{[1]}$ and Ikeuchi ${ }^{[14]}$ supported that ASTA supplied group showed lower weight gain compared to the only HFD group. Apart from these two, in the study of Yang et al. ${ }^{[15]}$, there were no differences in food intake, body weight and weight gain indiced amongst HFD and ASTA supplemented HFD fed groups. In this study, mice supplied with ASTA possessed the highest weight gain ratio. Taken together, the ability of ASTA in weight controlling should not be confirmed. Also, this ability might depend largely on the strain of mice model and their genetic, as the experiments were conducted on C57BL/6J, ddY and Swiss mice obtained different results.

To generate a diet-induced mice model, a higher energy source of fat (60\% energy from fat, D12492, Research Diet, USA) was used. With a 24-week trial, taking an extreme diet could lead to metabolic disorders and liver diseases in two groups of mice such as NASH, type II diabetes, insulin resistance or even cancer ${ }^{[16-18]}$. Hence, groups fed a high-fat diet easily got outsized compared to control group with a chow diet. Throughout the trial, ASTA supplied group showed an equal amount of food consumption with HFD group, but still the ratio of liver over body weight lowered at the end of the first phase compared to HFD. Besides, plasma cholesterol, uric acid and liver histology of AX were maintained lower/better than those of HFD, indicating that ASTA given along with the diet played a key role in preventing the progress of NAFLD and NASH. Other studies on the hepatosteatosis preventing effect of ASTA also indicated that with or without the weight, maintaining on HFD fed mice, ASTA lowered blood cholesterol, triacylglycerol, liver lipid accumulation and inflammation ${ }^{[1,15,19,20]}$.

To further clarify the mechanism of ASTA, gene expression in liver tissue was performed by semiquantitative RT-PCR (Fig. 3). It could be inferred that when taking a long-term high-fat diet, both PPAR $\alpha$ and $\gamma$ level had an inclining trend. PPAR $\alpha$, the main factor that regulating free fatty acids, involves in maintaining body weight and protecting from diet-induced obesity and/or diabetes ${ }^{[21-23]}$. In other words, the rising of PPAR $\alpha$ level in mice fed a high-fat diet was a protective mechanism. Together, the differences in growth ratio and liver PPAR $\alpha$ level of HFD and AX group could be clearly explained. As in Jia's study, although the relationship was not mentioned and mechanisms left unclear, but the ability of weight, maintaining of ASTA could be due to the enhanced expression of PPAR $\alpha$. In case of PPARY, ASTA supplement showed to protect liver tissue from steatosis, inferred from the inclining of liver PPARy level after ASTA was terminated. In obese mice or mice fed a high-fat diet, the over expression of PPARy proven to be related with liver inflammation and steatosis [24,25]. Collectively, in our study, ASTA treatment tended to affect the hepatitis steatosis through down-regulation of PPARy rather than activation of PPAR $\alpha$. Thus, leading to the result of an over growth in mice supplied with ASTA but absence of NAFLD signs.

\section{CONCLUSIONS}

The supplementation of ASTA on Swiss mouse model caused exceeding growth of mice because of the change in energy metabolism. Nevertheless, the efficacy of ASTA on the liver was in contrast to weight gain had proven through the liver/body weight ratio and PPARs semi quantitative RT-PCR results. The reduced liver weight was down due to regulation of PPAR $y$ and vice versa. Thus, the main gate-keeper of weight gain and liver weight was based on PPAR $y$ rather than PPAR $\alpha$ in Swiss mouse model fed a high-fat diet.

This project opened an insight into how ASTA could prevent and/or treat NAFLD. However, to reduce the burden of obesity and related diseases, further researches needed to be performed, especially in combining ASTA with other compounds that help in weight control.

\section{ACKNOWLEDGMENTS}

This research did not receive any specific grant from funding agencies in the public, commercial, or not-forprofit sectors.

\section{CONTRIBUTION OF AUTHORS}

Research concept- Duy Nguyen-Le, Hieu Tran-Van

Research design- Duy Nguyen-Le, Hieu Tran-Van

Supervision- Hieu Tran-Van

Materials- Hieu Tran-Van, Thuoc Linh Tran

Data collection- Duy Nguyen-Le, My-Tien Ngo, MinhTuan Vo

Data analysis and Interpretation- Duy Nguyen-Le, Duy Nguyen-Le, My-Tien Ngo, Minh-Tuan Vo 
Literature search- Hieu Tran-Van, Duy Nguyen-Le, MyTien Ngo

Writing article- Duy Nguyen-Le, My-Tien Ngo, Hieu TranVan

Article editing- Duy Nguyen-Le, My-Tien Ngo, Hieu TranVan

Critical review- Hieu Tran-Van

Final approval- Hieu Tran-Van

\section{REFERENCES}

[1] Jia Y, Wu C, Kim J, Kim B, Lee SJ. Astaxanthin reduces hepatic lipid accumulations in high-fat-fed C57BL/6J mice via activation of peroxisome proliferatoractivated receptor (PPAR) alpha and inhibition of PPAR gamma and Akt. J. Nutr. Biochem., 2016; 28: 9-18.

[2] Peeters A, Baes M. Role of PPAR $\alpha$ in Hepatic Carbohydrate Metabolism. PPAR Res., 2010; 2010: 112.

[3] Zhang W, Sun Q, Zhong W, Sun X, Zhou Z. Hepatic Peroxisome Proliferator-Activated Receptor Gamma Signaling Contributes to Alcohol-Induced Hepatic Steatosis and Inflammation in Mice. Alcohol. Clin. Exp. Res., 2016; 40(5): 988-99.

[4] Tailleux A, Wouters K, Staels B. Roles of PPARs in NAFLD: Potential therapeutic targets. Biochim. Biophys. Acta., 2012; 1821(5): 809-18.

[5] Liss KH, Finck BN, PPARs and nonalcoholic fatty liver disease. Biochim., 2017; 136: 65-74.

[6] Chalasani N, Younossi Z, Lavine JE, Charlton M, Cusi $K$, et al. The diagnosis and management of nonalcoholic fatty liver disease: Practice guidance from the American Association for the Study of Liver Dis., 2018; 67(1): 328-57.

[7] Bhatt H, Smith R, Fatty liver disease in diabetes mellitus. Hepatobiliary. Surg. Nutr., 2015; 4(2): 10108.

[8] Corrales P, Vidal-Puig A, Medina-Gómez G. PPARs and Metabolic Disorders Associated with Challenged Adipose Tissue Plasticity. Int. J. Mol. Sci., 2018; 19(7): 2-16.

[9] S. Bhuvaneswari E, Arunkumar P, Viswanathan CV, Anuradha A. Astaxanthin restricts weight gain, promotes insulin sensitivity and curtails fatty liver disease in mice fed a obesity-promoting diet. Process Biochem., 2010; 45(8): 1406-14.

[10]KimS, Sohn I, Ahn JI, Lee KH, Lee YS, et al. Hepatic gene expression profiles in a long-term high-fat diet- induced obesity mouse model. Gene, 2004; 340(1): 99-109.

[11]Marone M, Mozzetti S, Ritis D, Pierelli L, Scambia G, Semiquantitative RT-PCR analysis to assess the expression levels of multiple transcripts from the same sample. Biol. Proced., 2001; 3(1): 19-25.

[12]Robert R, Maronpot R, suhiko K, zawa Y, Nyska A, Hepatic enzyme induction. Histopathol. Toxicol. Pathol., 2010; 38(5): 776-95.

[13]Patsouris D, Reddy J, Müller $M$, Kersten S, Peroxisome proliferator-activated receptor $\alpha$ mediates the effects of high-fat diet on hepatic gene expression. Endocrinol., 2006; 147(3): 1508-16.

[14] Ikeuchi M, Koyama T, Takahashi J, Yazawa K, Effects of Astaxanthin in Obese Mice Fed a High-Fat Diet. Biosci. Biotechnol. Biochem., 2007; 71(4): 893-99.

[15]Yang Y, Pham TX, Wegner CJ, Kim B, Ku CS, et al. Astaxanthin lowers plasma TAG concentrations and increases hepatic antioxidant gene expression in diet-induced obesity mice. Br. J. Nutr., 2014; 112(11): 1797-804.

[16]Hill-Baskin AE, Markiewski MM, Buchner DA, Shao $H$, DeSantis D, et al. Diet-induced hepatocellular carcinoma in genetically predisposed mice. Hum. Mol. Genet., 2009; 18(16): 2975-88.

[17]Van-Saun M, Lee I, Washington M, Matrisian L, Gorden D, High Fat Diet Induced Hepatic Steatosis Establishes a Permissive Microenvironment for Colorectal Metastases and Promotes Primary Dysplasia in a Murine Model. Am. J. Pathol., 2009;175(1): 355-64.

[18]Nakamura A, Tajima K, Zolzaya K, Sato K, Inoue R, et al. Protection from non-alcoholic steatohepatitis and liver tumourigenesis in high fat-fed insulin receptor substrate-1-knockout mice despite insulin resistance. Diabetologia, 2012; 55(12): 3382-91.

[19]Ni Y, Nagashimada M, Zhuge F, Zhan L, Nagata N, et al. Astaxanthin prevents and reverses diet-induced insulin resistance and steatohepatitis in mice: $A$ comparison with vitamin E. Sci. Rep., 2015; 5.

[20]Curek GD1, Cort A, Yucel G, Demir N, Ozturk S, et al. Effect of astaxanthin on hepatocellular injury following ischemia/reperfusion. Toxicol., 2010; 267(1-3): 147-53.

[21] Costet P1, Legendre C, More J, Edgar A, Galtier P, et al. Peroxisome proliferator-activated receptor alphaisoform deficiency leads to progressive dyslipidemia 
with sexually dimorphic obesity and steatosis. J. Biol. Chem., 1998; 273(45): 29577-85.

[22]Vázquez M, Merlos M, Adzet T, Laguna J, Decreased susceptibility to copper-induced oxidation of ratlipoproteins after fibrate treatment: influence of fatty acid composition, Br. J. Pharmacol., 1996; 117(6): 1155-62.

[23]Mancini FP, Lanni A, Sabatino L, Moreno M, Giannino $A$, et al. Fenofibrate prevents and reduces body weight gain and adiposity in diet-induced obese rats. FEBS Lett., 2001; 491(1,2): 154-58.
[24]Moran-Salvador E, Lopez-Parra M, García-Alonso V, Titos $E$, Martínez-Clemente $M$, et al. Role for PPAR in obesity-induced hepatic steatosis as determined by hepatocyte- and macrophage-specific conditional knockouts. FASEB J., 2011; 25(8): 2538-50.

[25]Yu S, Viswakarma N, Batra SK, Sambasiva Rao M, et al. Adipocyte-specific gene expression and adipogenic steatosis in the mouse liver due to peroxisome proliferator-activated receptor gamma1 (PPAR gamma1) overexpression. J. Biol. Chem., 2003; 278(1): 498-505. 